\title{
La resistencia social India y el bien de todos. Aportes de Gandhi para una economía noviolenta
}

\author{
Óscar Useche \\ Uniminuto, Bogotá, Colombia. \\ Email: ouseche@uniminuto.edu
}

\begin{abstract}
Resumen: ${ }^{1}$ Gandhi y el movimiento satyagrahi marcaron un hito en las luchas por la descolonización y la resistencia social de los pueblos. Este artículo presenta algunos de los acontecimientos que definieron el devenir del proceso noviolento de la India centrándose en el examen de su aportes en la dimensión de una economía del bien de todos basada en la potencialidad de los pequeños productores y de las redes comunitarias. Se analiza el impacto de la política gandhiana a través de su Programa Constructivo de la India y los aprendizajes que dejan sus principios y prácticas económicas novedosas asentadas en la cultura y en la fuerza ética de su verdad.
\end{abstract} cia Social.

Palabras clave: Economía noviolenta; Gandhi; Bienes Comunes; Resisten-

\section{Social resistance in India and the well being for all. Gandhi's contributions for a nonviolent economy}

\begin{abstract}
Gandhi and the satyagrahi movement set a milestone in the struggle for decolonization and social resistance process. This study presents some of the events that set the development of the nonviolent process in India, focusing on the assessment of its contribution to the economy based on the potentiality of small producers and community networks. The impact of the Gandhian politics is analyzed based on its Indian Constructive Program and its lessons regarding new economic principles seated on the culture and on the ethical strength of its truth.

Keywords: Nonviolent Economy; Gandhi; Common goods; Social resistance.
\end{abstract}

\section{Resistência social indiana e o bem de todos. Contribuiç̧̃es de Gandhi para uma economia não-violenta}

Resumo: Gandhi e o movimento satyagrahi foram um marco na luta pela descolonização e a resistência social dos povos. Este artigoa presenta alguns dos acontecimentos que definiram a evolução do processo de luta não-violenta na Índia concentrando-se emanalisar as suas contribuições para o tamanho de uma economia para o bem de todos com base no potencial dos pequenos produtores e redes comunitárias. Analisa-se o impacto da política de Gandhi através do seu Programa Construtivo da Índia e os aprendizados que deixam seus princípios e práticas 
econômicas inovadoras sustentadas na cultura e na força ética de sua verdade.

Palavras-chave: Economia não-violenta; Gandhi; Bens Comuns; Resistência social.

\section{Introducción}

Si hay un hecho novedoso para el pensamiento social contemporáneo es el de que esté trasladando su foco de atención hacia la emergencia de formas creativas con que las comunidades afrontan los nuevos procesos de producción material y simbólica. Tal problematización emerge de la cultura y de las relaciones que se tejen en el campo social al calor de una multiplicidad de luchas históricamente sucedidas que proporcionan evidencias de su capacidad de resistir deviniendo potenciales nuevas maneras de existir.

Las sucesivas y profundas crisis de los países centrales demuestran los límites de la racionalidad económica moderna y del gobierno del capital y la amenaza de que su expansión desbocada, agenciada principalmente por las leyes de la ganancia, se conviertan en un desastre para las distintas formas de vida sobre el planeta (Martínez Hincapié, 2012). El que un puñado de individuos y corporaciones codiciosas, abusando del poder del que disponen, se hayan apropiado de la riqueza social mundial incrementando la explotación del trabajo y el saqueo de los bienes naturales, indica la pobreza de la democracia que hemos construido y el fracaso de la llamada autorregulación de los mercados a partir de la competencia que se proclamó hace más de tres décadas.

Uno de los ángulos del problema es el que la noción de lo público en la modernidad se haya puesto en cuestión. El desmoronamiento de los "Estados de bienestar" y la caída del mundo del socialismo real soviético dieron el paso al neoliberalismo y develaron la simplificación que se había hecho de lo público bajo el monopolio estatal, así como la insuficiencia de la diferenciación clásica de éste con el ámbito de los asuntos privados. Hoy se abre un abanico de nuevas modalidades de constitución de lo común, concepto que desborda y resignifica lo público.

La noción de "lo común” hace alusión al bienestar y a la riqueza que son concurrentes a todos los miembros de una sociedad históricamente dada; por supuesto entre ellos se incluyen los bienes comunes materiales que provienen de la naturaleza (agua, aire, biodiversidad). Pero también este concepto hace referencia a los resultados de "la producción social que son necesarios para la interacción social [...] tales como saberes, lenguajes, códigos, información, afectos [...] y a las prácticas de interacción cuidado y cohabitación en un mundo común” (Hardt, Negri, 2011: 10).

La cuestión es que el paradigma del desarrollo económico del pro- 
yecto modernizador de las sociedades occidentales determinó un particular tipo de poblamiento de los territorios, de apropiación de los bienes naturales, de desacralización del vínculo con la tierra, de consumismo como elemento básico de la distribución, todo con un elevado costo ecológico y social. Es pues interés de este artículo indagar sobre algunos elementos que puedan producir la reconstitución de los vínculos sociales y ambientales que se entretejen en medio de la lucha por la defensa de la dignidad y la diversidad de las comunidades.

Resistiendo a la homogenización promovida por el capital, y a la fuerza con que se universalizan los mercados, miles de experiencias constituyen poderes generados en los márgenes, cuyos sujetos son enunciaciones minoritarias que se plantean consolidar su potencia creativa, hacer respetar su modo de vivir y de relacionarse, preservar su memoria y afirmar su singular construcción del territorio. Parte de ello son los aspectos relacionados con los modos de producir y con la esfera económica que no puede explicarse sin atender a su imbricación con las relaciones sociales, con las formas de encuentro con el mundo natural y con la cultura. La producción económica, hay que enfatizarlo, es producción cultural en tanto expresa tradición, lenguajes, sentidos, una manera particular de vincularse con el pasado, con lo ancestral y una determinada afirmación de modos de vida.

Así por ejemplo, por ceñirnos sólo al continente latinoamericano, los indígenas de los Andes americanos han experimentado otras economías, revalorizando tradiciones de organización social y productiva como las que dieron origen del "buen vivir” (Sumak Kawsay en Quechua, Suma Qamaña en Aymara), que se practica en las comunidades indígenas del continente. En otra dimensión, se han desarrollado experiencias de resistencia desde la tierra y la producción campesina como la del Movimiento Sin Tierra en Brasil. En el ámbito urbano, colectivos argentinos, brasileños y uruguayos han proporcionado ricos aprendizajes al dar otro tratamiento al dinero, despojarlo de su forma fetichista mercantil y asumirlo como moneda social. A este tipo de expresiones las he denominado "economías en resistencia” y su naturaleza está generalmente vinculada a la perspectiva y a los métodos de la noviolencia, desentrañando claves para la reconstitución de lo común.

Pese a la importancia del problema, la investigación sobre la pertinencia y amplitud de los ejercicios de economías populares y comunitarias, que se plantan como economías en resistencia, sigue siendo incipiente. Este artículo procura entonces aportar a la indagación sobre cómo ellas, al desplegar una dimensión profunda de la vida en la producción de bienes y servicios, materiales e inmateriales, ligada al alimento, a la tierra, al agua, a la conservación de la biodiversidad y del planeta mismo, se incorporan a las resistencias en la esfera política, o a formas de resistir manifiestas en la densificación de las redes sociales, o en la producción de subjetividades de cambio en clave micropolítica². 
Tales asuntos se plantearon, con gran claridad, en las primeras décadas del siglo XX, cuando Gandhi, su partido y el pueblo indio iniciaron su lucha noviolenta (satyagraha) por la independencia de la India. La importancia de este movimiento estuvo en el descubrimiento de nuevos caminos para desprenderse del colonialismo, así como la irrupción de nuevas miradas e intentos que hicieran posible generar alternativas económicas sustentables y coherentes con su filosofía de transformación.

En ese sentido, el gandhismo fue pionero en explorar estos mundos nuevos y sus aprendizajes cobran mucha actualidad para las resistencias contemporáneas. Examinaremos brevemente para ello la puesta en marcha del Swadeshi (autonomía local) impulsada por Gandhi en el curso de la revolución noviolenta anticolonial de la India y de su propuesta de Sarvodaya (bien común o bien de todos) que hicieron parte de su Programa Constructivo de la India.

Este artículo se refiere inicialmente a algunos de los acontecimientos que marcaron el devenir del proceso noviolento de la India leídos en clave genealógica. Luego aborda algunos elementos sobre el entorno de la economía colonial india en discusión con algunos autores de la escuela de los estudios culturales y finaliza analizando el impacto de la política gandhiana a través de su Programa Constructivo. Se cierra con algunas conclusiones sobre la actualidad de varias de las tesis centrales del planteamiento económico de Gandhi.

\section{La noviolencia como poder de los sin-poder}

El Mahatma Gandhi rasgó la historia de las guerras y emprendió con el pueblo indio la gran marcha por la independencia de la tutela colonial del Imperio británico y la transformación de esa sociedad milenaria. Inventó en ese proceso la noviolencia como movimiento social y político de gran impacto, como acción colectiva emancipadora de resistencia.

Todo el esfuerzo del movimiento gandhiano consistió en identificar e impulsar un conjunto de prácticas que contribuyeran a configurar la noviolencia como un campo de experimentación y de construcción del pensamiento resistente moderno adecuado a las condiciones de la India. Para ello recuperó la tradición de la ahimsa presente en las culturas indostánicas (jainismo, budismo e hinduismo) y las puso en diálogo con otras maneras de nombrar la noviolencia entre los partidarios de la desobediencia civil, los abolicionistas de la esclavitud, los pacifistas religiosos y los “no-resistentes", entre otros. Así, la noviolencia se fue configurando como una propuesta de gran profundidad que consiguió una formulación compleja e integral que conjugaba consideraciones morales, una convocatoria a desplegar la potencia espiritual de los indios y unas prácticas novedosas de la política. Para que esta operación constituyera los sujetos de la revolución noviolenta se promovió el deber de cada quien de trabajar sobre el gobierno de sí mismos, sobre la 
propia experiencia en la búsqueda de la verdad y en la resistencia al poder constituido.

La lucha de independencia de la India, conducida por Gandhi, y el desenlace de la expulsión de los ingleses en 1947, va a recorrer un largo camino de ensayos y de lucha no solo contra el colonialismo británico sino por conseguir la unidad de las fuerzas indias. Dentro de ellas había fuertes debates con tendencias proclives a entender la modernización como implantación del modelo industrialista occidental, o, de otra parte, a asumir la lucha como una insurrección violenta. El gandhismo planteó un programa de construcción del nuevo país, sin que hubiera que esperar a que los ingleses abandonaran la India. Eso implicaba también la asignación de un lugar preeminente a la desobediencia civil como método eficaz para resolver problemas locales concretos, pero también para enfocarse en la decisiva finalidad de alcanzar la liberación.

El Programa Constructivo fue la propuesta gandhiana para la creación de un nuevo mundo para la India; materializaba el norte estratégico de que la independencia no era algo exterior a la India y a los indios, no era solo un problema de cómo expulsar a los ingleses. El ejército británico se retiraría de la India cuando la fuerza interna del pueblo indio les hiciera imposible gobernar, cuando la superioridad moral de los resistentes se manifestara en capacidad propia de autogobierno, cuando el poder paralelo que se estaba gestando se volviera hegemónico. Aspectos centrales del Programa Constructivo solo pudieron impulsarse en gran escala cuando el gobierno postbritánico autorizó a Vinoba Bahve, discípulo de Gandhi, la entrega de tierras a más de 30 millones de campesinos para reivindicar a esa fuerza social en la que el Mahatma había depositado sus principales energías y entre los cuales había desarrollado su ensayos de micropolítica autogestionaria. No obstante, la deriva del nuevo país, ya dirigido por Nehrú y el Partido del Congreso, se enfocó a construir una India capitalista y nuclear (Hobsbawm, 1998).

Para Gandhi había que demostrar que la nueva India no era cuestión del futuro, que palpitaba en todos los embriones de la resistencia política, económica, comunitaria y espiritual. Este era el principal componente del nuevo poder, su potencia constructiva, no tanto su capacidad de oposición, de boicot y de causar daño al imperio. Tal fue el arte de la resistencia noviolenta que aprendieron los indios a su lado junto a los satyagrahis, buscadores de la verdad.

Se requería levantar el discurso del débil que le reprocha al fuerte la injusticia, que es una práctica de pronunciar verdad, que va configurándose como un logos, una manera de decir y de pensar razonablemente sobre el mal social que desata el poderoso. Hoy podemos hacer la genealogía de esas prácticas, evaluarlas a la luz de un análisis hecho desde el presente, y constatar que su punto de partida fue el de confiar en el poder de la gente, en su capacidad para dar forma a su propia conducta, rebelándose contra las normas de subordinación imperantes, y constituyendo su propia fuerza de decisión para edificar un camino autónomo. 
La revolución noviolenta sería entonces la de los hombres y las mujeres "sin-poder", capaces de destituir la tiranía y poner fin al colonialismo a través de la resistencia civil de masas (Satyagraha) (López Martínez, 2012), que fue mucho más allá de simples métodos de persuasión o de manifestar el poder de la palabra, sino auténticos modos de existir autónomos, distanciándose de la violencia física para enfrentarse al dominador y absteniéndose de matar, aún teniendo la capacidad para hacerlo.

Gandhi fue uno de los primeros líderes que reinterpretó a La Boethie (2007) y Thoreau (2004), usando el no consentimiento y la paralización del gobierno -no por la vía militar- sino retirándole la cooperación y la lealtad. Así el poder nace de allí, no de la violencia, ni del fusil; y la fórmula de la dominación y dirección del Estado que habría de plantear Gramsci como: violencia + consenso, sería descompuesta por Gandhi para plantear que el poder es la combinación de consenso + noviolencia. La legitimidad de un poder, según lo expresado por Gramsci deviene de su capacidad para crear una hegemonía intelectual y moral que soporte el consenso de la clase dirigente dado que el ejercicio de la violencia solo sostiene clases dominantes. Si se sigue la estructura gramsciana el fundamento de Gandhi sería la noviolencia que propende por la creación de un campo de contra-hegemonía cultural establecida sobre la fuerza de la verdad (satyagraha) que conduce no a la derrota del "enemigo" sino a la persuasión y convencimiento del adversario

Se trastocaban así las ideas sobre la acumulación de fuerzas pues se trataba, ante todo, de comprender a profundidad el grado de preparación y fortaleza de la gente común para hacer parte de un acontecimiento revolucionario no armado, para alejarse de la pasividad y conseguir "un estado intensamente activo, más activo que la resistencia física o la violencia”, como lo dijera Gandhi en “Young India” en 1920.

Pero además, hace falta la resistencia como acto de creación, como afirmación de la potencia propia, algo que no se puede desprender solo de la negativa a seguir haciendo parte de un imperio, o de un acto que, bajo presión, reconociera que, en adelante, Inglaterra e India serían dos naciones distintas. Con estos argumentos y tales pensamientos fundados en la fuerza de la verdad (satyagraha) y en la noviolencia (ahimsa), emanados de la experiencia y del vínculo con su pueblo, Gandhi y el gandhismo van a enfrentar la lucha por la independencia y la radical transformación social de la India y a desarrollar otros conceptos y formas de lucha como el swaraj (autodeterminación, autogobierno, independencia), swadeshi (autonomía local, autocontrol, autosuficiencia) y sarvodaya (bien común o bienestar de todos ) (Pontara, 2004).

Barrington Moore señala además un hecho que estuvo en el centro de la movilización gandhiana, esto es los campesinos y sus formas comunitarias de producción: "Como implicaba el concepto de Swadeshi, el eje del programa de Gandhi fue la revivificación de la comunidad aldeana tradicional. Era con los campesinos con quienes armonizaba de verdad el corazón 
de Gandhi, y fueron ellos quienes respondieron de un modo más entusiasta a su movimiento (...)” (Moore, 2002: 534-535).

\section{El problema de la modernización en el mundo cultural subalterno de las colonias}

Se discute mucho sobre la inevitabilidad de la disolución de las sociedades pre- modernas. Visto desde la óptica europea, la ocupación violenta de territorios como la India tenía como consecuencia trasladar a sus colonias el influjo del progreso y la civilización. Incluso desde posiciones críticas como la de Marx no había porqué lamentar la desaparición de estas formas, que él denominaba "pequeñas comunidades semi-bárbaras y semicivilizadas", propias de lo que podría concebirse como "el modo de producción asiático". En "La dominación británica en la India” (1853) el filósofo socialista alegaba que lo que la intromisión colonial había conseguido en el Indostán era colocar en competencia directa:“(...) al hilador en Lancashire y al tejedor en Bengala, lo que barrió tanto al hilador hindú como al tejedor hindú, disolvió esas (comunidades), al hacer saltar su base económica, produciendo así la más grande, y, para decir la verdad, la única revolución social que jamás se ha visto en Asia”. (Marx, 2000: https://www.marxists.org/ espanol/m-e/1850s/25-vi-1853.htm).

La interpretación que Marx hace en estos pasajes sobre la naturaleza de la sociedad india plantea un problema epistemológico que ha sido debatido por los autores pertenecientes a la escuela de los "estudios subalternos” y otros teóricos de la corriente de la post-colonialidad ${ }^{3}$. Tal problema se deriva del enfoque eurocéntrico, y de un humanismo propio de la ilustración, del que el enfoque marxista es subsidiario, pero que abarca con mayor radicalidad todas las corrientes cartesianas, positivistas y estructuralistas que dominaron el pensamiento occidental moderno.

Según ellas, todas las formaciones sociales, incluyendo las de las sociedades coloniales en donde el capitalismo no ha emergido aún, o es todavía muy incipiente, pueden ser conocidas y hacerse comprensibles solamente a partir de categorías teóricas de naturaleza universal como "el capital”. Esto por cuanto "la sociedad burguesa es la más compleja y desarrollada organización histórica de la producción”, y, por tanto, "Las categorías que expresan sus condiciones y la comprensión de su organización permiten al mismo tiempo comprender la organización y las relaciones de producción de todas las formas de sociedad pasadas (...)” (Marx, 1975: 26).

Este mismo análisis se hace para evaluar las formas políticas; de tal manera que los modos de ser liberales, parlamentarios y de las soberanías nacionales se toman como los patrones de modernidad o atraso de las sociedades coloniales, incluyendo el patrón del ciudadano libre que, como dice la investigadora de los estudios subalternos G. Spivak, "es el sujeto 
legal del pensamiento de la ilustración y está contenido dentro de la categoría "capital" 4 .

Por supuesto Marx consigue niveles de análisis complejos y diferenciales sobre las realidades de ese "modo de producción asiático", perfeccionando un método de estudio que se distingue del mucho menos refinado de las tendencias marcadas por un escueto y tosco pensamiento colonial. Los investigadores de la subalternidad denuncian que estos últimos pretenden escribir la historia y representar “(...) los pasados indios mediante una narración homogeneizadora de una transición desde un periodo "medieval” hacia la “modernidad”. (Chakrabarty, 1999).

La institucionalización del poder británico, una vez concluida la era del dominio de la “Compañía de las Indias Orientales”, tendió a presentar a la Corona como un agente de modernización que otorgaría la ciudadanía a los indios que en adelante podrían ser considerados "súbditos de su majestad" en un "Estado de derecho" regido por un mandato constitucional, la separación de poderes y la expansión de la "opinión pública”. Ahora bien, el problema no sería que Inglaterra estructurara su discurso de dominación colonial como un discurso de progreso y acceso a formas políticas liberales; sino que las élites indias ilustradas, que serían la base original del movimiento nacionalista, compartieran esa visión.

Por esta senda se da paso ya no solo a la colonización sino a la aparición de un pensamiento propio de una situación de colonialidad, en la que el coloniaje no es únicamente asunto de dominación física y de imposición forzada de valores y estilos de vida, sino que un sector de la población indígena, periférica, asume como su propio proyecto- incluso de descolonización- las subjetividades del centro metropolitano. De esta manera los nacionalistas indios de la segunda mitad del siglo XIX y principios del XX, educados en Europa, bilingües, urbanos y miembros de las castas superiores, encajaron en su condición de "sujetos de la nación”, pensados a la manera europea.

Algunos sospechaban de un modelo que daba nueva fuerza a las religiones y los imaginarios comunitarios en menoscabo del enfoque científico, del objetivismo y del progreso. La idea gandhiana de la rueca como símbolo nacional indio, así como el discurso anti-industrial de Gandhi los confundían y les generaban una sensación dual en la medida en que rechazaban, como conservadora, la idea de aferrarse a las tradiciones hinduistas para detener el progreso impulsado por los ingleses, pero reconocían como indiscutible el genio y la capacidad del Mahatma para conducir una lucha del tamaño y la singularidad de la que se vivía en la India.

He ahí el debate sobre la modernización del mundo de los subordinados, en este caso del mundo oriental. Para los intelectuales modernizantes el desarrollo no podría ser otra cosa entonces que tomar el camino de Occidente: maquinización, industrialismo, racionalismo, secularización, Estado nacional, parlamentarismo, reconstrucción de la soberanía del Uno, disolu- 
ción de las comunidades campesinas, urbanización. Repetir “algo que ya ha ocurrido en otra parte” ${ }^{5}$, en escala local y subalterna un guión ya trazado, conocido y probado para instalar el capitalismo, esta vez en su forma colonial; un capitalismo y una democracia moderna derivados, subordinados y poco originales. El modelo de modernización occidental se convirtió en el paradigma de las élites de los países coloniales para salir del atraso, para acudir al llamado del progreso, de la riqueza y la prosperidad.

La cultura hacía parte de ésta transformación ya que las culturas tradicionales, el apego a las religiones, las formas del entramado social, la pervivencia de las relaciones comunitarias solo podían entenderse como obstáculos para la occidentalización, fuentes de pobreza, de barbarie y despotismo. Por eso se ve como urgente instalar instituciones como la escuela, para difundir y aprender esos valores, para fortalecerse y hacerse capaces de conseguir lo que ya habían logrado los europeos, deshaciéndose de los valores tradicionales que supuestamente los hacían inferiores.

Es la enajenación propia de la colonialidad del pensamiento que ya analizaba Frantz Fanon al denunciar el quiebre de la relación del sujeto colonizado con su propia cultura y sus propias raíces, así como el olvido de su historia, hipotecada a la única historia que, a los ojos del colonizado, existe realmente: la que se desarrolla en Europa ${ }^{6}$.

El movimiento nacionalista de éstas élites era necesariamente homogeneizador, ya fuese desde la visión de los partidarios de la instauración del capitalismo (concebido como un régimen válido para cualquier sociedad), con la consiguiente imposición de una racionalidad burguesa válida para todos; o desde el punto de vista del papel que el marxismo asignaba a estos nacionalismos que debían eliminar los rezagos de comunidades y clases pre-capitalistas para dar paso a la dicotomía burguesíaproletariado.

\section{La prioridad de la autonomía y el respeto a la cultura india en la propuesta de Gandhi}

Las resistencias indias que confluyeron en la lucha anticolonial del gandhismo apuntaron menos a transformaciones jurídico-estatales que a reivindicaciones territoriales o de defensa de los modos de vida, abarcando, en ese sentido, un espectro mucho más amplio de la lucha, instalándose firmemente en las dimensiones culturales, simbólicas y productivas de las prácticas de emancipación.

Eso lo comprendió aguda y tempranamente Gandhi, impulsando la creación de un campo propio de la resistencia, articulando los deseos religiosos de la población, su vocación comunitaria, su tradición en la producción de bienes materiales y sus anhelos de independencia. No quería "hacer inglesa a la India”, ni tampoco que la revolución noviolenta significara 
mantener el mismo régimen de los ingleses pero ahora administrado por nativos indios.

Por eso cuando escribió HindSwaraj en $1908{ }^{7}$ decía algo muy provocador: "Siento que si la India eliminase la civilización moderna saldría ganando” y, más adelante recriminaba a los nacionalistas que están de acuerdo con que se marche Inglaterra, pero no con prescindir del progreso que habría traído a la India: “(...)Usted quiere la naturaleza del tigre sin el tigre; como decir convertir a la India en inglesa. Y cuando se vuelva inglesa no será llamada Indostán sino Englishtan. Este no es el Swaraj que deseo" (Gandhi, 2002: 225-236).

Con esta perspectiva la dirección del nacionalismo indio da un viraje hacia la esfera de lo cotidiano, allí donde se reproduce la subordinación pero, también, en donde es posible que emerja el acontecimiento extraordinario, el que rompe las temporalidades de la dominación y recrea el territorio de la resistencia, poniendo de cabeza el mundo colonial, al no permitir que la vida local fuera homogenizada por los tiempos universales del capitalismo colonial.

Gandhi va a llamar a recuperar los ritmos propios de la vida artesanal y campesina de los indios, esforzándose por controvertir la jerarquía temporal marcada por la aceleración del mundo industrial. Sus prácticas de ayuno, de su insistencia en la imposibilidad de prescindir de la cosmovisión hinduista, musulmana o sij. Así como tampoco dejar de tener en cuenta sus tiempos rituales, el peso que se le otorgaba a las manifestaciones de espiritualidad como una dimensión presente en la vida de la gente, en su comportamiento público y privado. Se negó a aceptar el proceso de secularización tal como lo concibieron los occidentales modernos, manteniendo, en cambio, la intersección de las esferas religiosas y políticas de la vida.

Todo eso para el gandhismo eran grietas de la dominación colonial, era lo que no había podido ser sometido a la autoridad jerárquica del pensamiento colonial, lo que permanecía como exterioridad del sistema dominante, lo que navegaba en otros tiempos y otros valores. Así, si bien otra parte de la sociedad india había sido absorbida por las lógicas coloniales, incluso una buena parte del movimiento nacionalista, éstas no habían podido ejercer la hegemonía sobre este inmenso mundo de lo tradicional, de lo local, de lo comunitario. Y este era también un pulso de poderes en el que, desde lo local, lo religioso, lo comunitario y lo cotidiano, se promulgaba la diferencia, lo heterogéneo, frente a la uniformización modernizante que postulaba el nacionalismo de élite.

El gandhismo confrontó de lleno la colonialidad del poder, primero en los ámbitos moleculares en donde el peligro de la colonización era inminente pero aún no había conquistado la predominancia, por lo que era posible apalancar líneas de fuga, esto es acomodarse en nichos propios para resistir el embate colonialista. Entendió que las luchas en el ámbito de los espacios representativos del poder serían solo la consecuencia de re- 
sistencias exitosas en las prácticas micropolíticas en donde se fraguaba la descolonización de la vida social.

Otro punto neurálgico fue la defensa de la comunidad aldeana india ${ }^{8}$, depurándola de sus rasgos más degradantes como el tratamiento que se daba a los intocables. Como consecuencia se produce la sintonía entre el gandhismo y la masa de los kisans (campesinos) que veían sus anhelos recogidos en el programa constructivo de la India, en el swaraj y el swadeshi. El historiador B. Moore lo describe así:

“Como implicaba el concepto de Swadeshi, el eje del programa de Gandhi fue la revivificación de la comunidad aldeana tradicional. Era con los campesinos con quienes armonizaba de verdad el corazón de Gandhi, y fueron ellos quienes respondieron de un modo más entusiasta a su movimiento (...)” (Moore, 2002: 534-535).

Pues bien, fue alrededor del programa constructivo y por la autonomía (Swaraj) gandhiana que se unificó el movimiento nacionalista; el Swaraj es el objetivo final de la nación y de la revolución noviolenta, haciendo honor a la etimología de éste término védico que puede ser traducido también como gobierno (raj) de sí mismo (Swa). Coherente con ello el Swaraj no puede operar sin la satyagraha, la fuerza del alma y del amor, que es la única arma legítima de la noviolencia (ahimsa).

En busca del Swaraj las calles de las ciudades de la India se vieron colmadas de no-cooperantes sentados en plazas y aceras, en actitud de meditación, que se negaban a levantarse a pesar de las golpizas que emprendieron las fuerzas del régimen. Gandhi renunció a las vestimentas de tipo occidental, o elaboradas con telas provenientes de las industrias inglesas y comenzó a usar el khadi, especie de manta hilada por él mismo y símbolo de la recuperación de lo propio. Convocó a toda la población a dejar de usar ropa extranjera así como a retomar la costumbre milenaria de fabricar su propia ropa e impulsar el aprendizaje de los niños(as) de este oficio.

Con eso llevaba a la práctica varios de los puntos que había consignado en el HindSwaraj: su crítica sin concesiones al modo occidental industrial de producción, la necesidad de romper el monopolio comercial inglés -que había arrasado con la pequeña industria artesanal india- declarándole el boicot y el replanteamiento de la economía del país, volviendo a las raíces campesinas y artesanas. Si en algo resentían los indios el yugo colonial era en los aspectos económicos, la extrema pobreza en que habían sido sumidos, la desaparición de sus medios de vida.

El Swaraj propulsó el renacimiento de las pequeñas industrias aldeanas. El uso de la rueca fue promovido como símbolo del distanciamiento del modo de los ingleses, la vuelta a la sencilla vida campesina y del renacimiento de las industrias autóctonas, tales como el hilado manual. Estos fueron los momentos culminantes de la primera fase de No-cooperación; con ello se llevaba al máximo grado el boicot de las telas extranjeras. 
Para Gandhi lo que estaba ocurriendo en el escenario de la independencia india era el rescate de la cultura de la no violencia, que para él era "más antigua que las montañas". Sobre esa base, en medio de la campaña de No- cooperación, el Congreso se lanzó a una febril actividad en el vasto medio rural del país procurando incorporar al movimiento las redes locales comunitarias, el tejido social con sus expresiones económicas y culturales y contribuir a transformarlas. Esto les permitía asumir la estructura tradicional de la sociedad, su conectividad y capilaridad, como el vehículo para agenciar el programa de Swaraj, que, como se ha dicho, era mucho más profundo que la independencia nacional.

\section{La sociedad del bien de todos (sarvodaya) encarnada en autonomías económicas locales (swadeshi)}

La lógica gandhiana iba dirigida a interpretar la resistencia como la capacidad de los indios de reconstruir su propia fuerza y comenzar a resolver, por sí mismos, los problemas atinentes a su propia existencia. Su potencia estaba en resistirse afirmando, construyendo, creando sus propios campos de acción autónoma, al exterior del territorio congelado de la colonización.

La comunidad era el campo relacional por excelencia para la noviolencia; de ahí la importancia de los proyectos experimentales de Gandhi en los ashram. Allí estaban las bases consuetudinarias de la solidaridad y del esfuerzo mancomunado que circulaban a través de conexiones subterráneas, de afinidades construidas durante siglos, de vínculos sanguíneos y lingüísticos con los que había operado la sobrevivencia, el esplendor y la decadencia, en los flujos constantes de la constitución de los territorios propios. El trabajo por el Swaraj va a transformarse en el ensayo cotidiano de la emergencia de otra posibilidad de ser para los indios.

La autonomía en lo local (swadeshi) se materializaba como una extensa confederación de aldeas autosuficientes y autogobernadas de carácter local y predominantemente rural. Esta es una idea plenamente libertaria que Gandhi describía al establecer su programa de sarvodaya (bien común, o bien de todos) que debía emerger en las aldeas indias:

"El centro era el ser humano y su plena ocupación, cada persona trabajaría para ganarse el pan, habría igualdad de oportunidades para todos, equidad de bienes materiales, descentralización, atención a las necesidades del más próximo, autosuficiencia en la alimentación y el algodón para las telas, respeto a todas las religiones” (Gandhi, 1982: 34-41).

Para estructurar su discurso sobre el bienestar y contrarrestar la creciente influencia del utilitarismo en las clases urbanas, y su contagio del movimiento nacionalista, Gandhi construye el concepto del bien de todos 
("sarvodaya")9. Justamente sarvodaya sería la búsqueda del mayor bienestar para "los últimos", esto es, los más golpeados por las condiciones de vida impuestas por el colonialismo. Esta es una convicción ética que propugna porque la riqueza de la sociedad sea distribuida para producir el bien de todos por igual. Siguiendo a Ruskin advierte que:

"Una injusticia conduce a muchas otras (...) La misma riqueza de la gente actúa como una maldición. La verdadera economía es la economía de la justicia. Las gentes estarán contentas en tanto aprendan a hacer justicia y a actuar con rectitud. Todo lo demás no solo es vano sino que conduce directamente a la destrucción” (Gandhi, 1977: 18-19).

Gandhi cree que la justicia es un problema de límites morales que transforman la economía de una ciencia de la pragmática del enriquecimiento individual en una ciencia moral de la redistribución y la equidad. Ahora bien, Gandhi entiende que el derecho a la igualdad de oportunidades no puede ser abstracto, porque "no todos tienen la misma capacidad". Entonces los de mayor capacidad y talento para producir mayor riqueza deben actuar como “depositarios y nada más”. Es decir, está bien alentar a los mejor dotados para que desplieguen su iniciativa individual y produzcan el mayor volumen de riqueza, pero ese mayor producto y valor debe ser usado en beneficio de todos, yendo a confluir en algo parecido a un "fondo común familiar”.

Esta idea gandhiana fue madurando hasta expresarse como una meta de la "economía noviolenta” que propende por una distribución igualitaria incluyendo en el "fondo común" el producto de quienes saben "cómo acumular riquezas”. El mecanismo para conseguir esto no sería la expropiación de los ricos ni arrebatarles sus riquezas por la fuerza, como plantearon las teorías clasistas de la revolución ("la expropiación de los expropiadores”), sino la conversión de estos en un tipo de fideicomisarios ${ }^{10}$ de su propio tesoro.

“(...) la distribución igualitaria se basa en la administración fiduciaria de los ricos, dada la riqueza superflua que poseen. Según esta doctrina, estos no pueden poseer una rupia más que sus prójimos. ¿Cómo se logrará esto? (...) el camino no-violento es evidentemente superior. Se le dejará al hombre rico la posesión de su riqueza, que utilizará razonablemente -según lo exijan sus necesidades personales- actuando como fideicomiso del resto para que la use la sociedad. En este planteo queda tácito que se cuenta con la honestidad del fideicomiso" (Gandhi, 1977: 20-21).

Con ello la sociedad se iría aproximando a una distribución igualitaria en donde todos(as) cuenten con los fondos necesarios para proveer sus bienes indispensables, aquellos que satisfacen "sus necesidades naturales y nada más”. La implantación de esta economía noviolenta no podía, por supuesto, ponerse a depender solo de la conversión y buena voluntad de 
los ricos para erigirse en "guardianes" y albaceas del bienestar de los pobres. Gandhi no dudaba de que una buena parte de las clases privilegiadas se resistirían a abandonar pacíficamente sus prerrogativas y persistirían en aplastar a los más débiles sumiéndolos en el hambre y la pobreza absoluta. La solución era la acción directa noviolenta de los pobres, la no-cooperación y la desobediencia civil hacia los ricos explotadores; en esto también proclama el gandhismo un discurso coherente y despojado de la candidez política que algunos le atribuyen.

"El rico no puede acumular riquezas sin la cooperación social del pobre. Si este concepto penetrara y se expandiera entre los pobres, estos se volverían más fuertes y aprenderían a liberarse, mediante la no-violencia de las aplastantes desigualdades que los llevan al borde de la inanición (...) Un devoto del ahimsa no puede suscribir la fórmula utilitaria (el mayor bien del mayor número). Tiene que luchar por el mayor bien de todos y morir en el intento de realizar ese ideal (...). Lo que debemos fomentar (...) no es el bien de unos pocos ni tampoco el bien de muchos, sino el bien de todos” (Gandhi, 1977: 2122, 24).

Son dos entonces los elementos fundantes de la sociedad sarvodaya: el fideicomiso y el aseguramiento de los bienes comunes para que la gente no sufra por falta de comida ni de ropa; ambos entrañan nuevas formas de organización social. El orden capitalista no puede gestar un orden igualitario, menos aún si su divisa es el utilitarismo. El fideicomiso es una oferta de la ahimsaa los ricos para que, al asumir los procesos que le permitan reformarse, se incorporen al tránsito hacia una economía noviolenta.

El orden económico de la sarvodaya observa que es el trabajo digno el que puede dar acceso a los bienes básicos preferentes. Por eso, el salario mínimo justo y la fijación de límites para una renta máxima hacen parte de "la corriente de la justicia” que hace posible preservar y compartir la prosperidad y la felicidad; estos factores no pueden ser regulados por la competencia:

“(...) encontramos que los economistas están equivocados en pensar que la competencia es buena para la nación. La competencia pone en situación de que el adquiriente compre el trabajo por un precio injustamente bajo, con el resultado de que el rico se vuelve más rico y el pobre más pobre. A la larga esto conduce a que la nación vaya a su ruina. El trabajador tiene que recibir un salario justo, de acuerdo con su capacidad (...)” (Gandhi, 1977: 17-18).

La producción y circulación de los bienes estarán determinadas por la necesidad social y por los imperativos éticos y no por el deseo de enriquecimiento personal a costa de los demás. Hay en todo esto un sentido del deber y de la urgencia de avanzar hacia un orden económico noviolento que, a la vez, nos amonesta sobre la condición violenta de toda forma de explotación y del uso abusivo o despilfarrador de los bienes que nos suministra la naturaleza. Las miles de comunidades auto-suficientes fundadas 
en el autogobierno, en la democracia y la cultura locales eran la base de esa especie de socialismo indio, autóctono y fundado en el sentido común. El Programa Constructivo para la India, sería el formato en que se vaciarían estos conceptos.

\section{Algunas conclusiones: aprendizajes de las bases de economía noviolenta del gandhismo}

El "Programa constructivo" sería el encargado de ordenar la visión gandhiana, un destacado intento por imaginar mundos políticos por fuera del canon liberal predominante, algo equivalente, en la crítica al capitalismo de Occidente, a lo hecho por Fourier, o Thoreau. El uso de la noción de Swadeshies aquí muy relevante pues implica el reconocimiento del valor de lo propio, tener confianza en la propia creación, fiarse de sí mismo y de su cultura, saber dónde radica la propia fuerza de cada cual y de cada comunidad. El Swadeshi hace referencia entonces a la autosuficiencia económica, rompiendo los lazos de dependencia basados en una economía ajena que esquilma el trabajo indio y hace mofa de sus manifestaciones culturales.

Hoy se reconoce desde variadas corrientes de pensamiento el valor de lo aportado por el gandhismo. Boaventura de Sousa Santos señala que:

“(...) la formulación de alternativas basadas en culturas no hegemónicas sigue una tradición de pensamiento y acción que tuvo sus manifestaciones más importantes en la lucha contra el colonialismo. Probablemente, el ejemplo más destacado sea la idea del swadeshi, elaborada por Gandhi en el contexto de la lucha del pueblo indio contra el colonialismo británico” (Santos, 2011).

Lo singular es el privilegio dado a la producción de los medios de subsistencia básicos y dar empuje de la comunidad a partir del uso de los recursos disponibles; eso, para Gandhi, incuba autodeterminación. Expandir la aplicación de principios de cooperación según la fórmula: “(...) cada aldea debe producir todo lo necesario y un porcentaje más para las necesidades de la ciudad” (Gandhi. 1977: 309). Esto en lugar de reproducir la locura del consumo indeterminado que requiere de una espiral sin fin que alienta el productivismo y el imperio del dinero.

Claro que el Swadeshi plantea formas de intercambio y de circulación de productos, sólo que esto se hará con formas de comercio justo a diferentes escalas, condicionadas a consideraciones éticas, cuya base es la noviolencia. Esto porque, a su entender, no existe el "puro motivo económico" que expuso la economía política clásica para defender la fuerza económica que estaría contenida en el egoísmo:

"La verdadera economía, dice, nunca conspira contra las normas éticas más elevadas, así como la verdadera moral, para merecer su 
nombre, tiene que ser al mismo tiempo una buena economía. La economía que (...) permite que el fuerte acumule riquezas a expensas del débil es una ciencia falsa y funesta. Suena a muerte. La verdadera economía, por otra parte, favorece la justicia social, suscita el bien de todos por igual, incluyendo al débil y es indispensable para una vida decente" (Gandhi,: 1977: 16-17).

La vida, en su conjunto, es el campo sobre el que se emplaza cualquier proceso productivo. El trabajo vivo, con toda su multiplicidad y diferencia, es la fuerza principal para la reproducción de la vida humana y la preservación de otras formas de vida.

Hay entonces que recabar en la experiencia, en esos "estados vividos” en donde habitan verdaderas escuelas de vida. Y allí trabajar por el acontecimiento, por la irrupción de lo inesperado, por lo que genera el impulso creador, la invención, por lo que reintegra el trabajo con la vida. Para las subjetivaciones dominantes y su gran máquina de comunicación esto no es más que una ensoñación ingenua.

¿Cómo opacar la eficacia contundente del capital para ordenar la vida? Pero es que el capital, como el soberano estatal, viven del excedente del trabajo, del saber y del esfuerzo humanos. Su milagro económico reside en la capacidad de capturar la inmensa energía social, y codificarla en clave de competencia, de plusvalía, de lucro y de segmentaciones binarias. El sistema productivo organizado por el capital, con sus ansias de crecimiento sin fin, se convirtió en una auténtica máquina de guerra que coloca en la condición de enemigo cualquier intento disidente por dar otro formato a la economía, por intentar otras posibilidades.

La crisis del modelo de desarrollo occidental ha marcado unos límites y ha cuestionado, como lo hiciera Gandhi, las nociones del crecimiento, del progreso y de la prosperidad. Ninguno de los problemas abordados por el gandhismo en esta materia son ajenos a la discusión actual y algunos comienzan a ser enfocados desde lógicas noviolentas cercanas a las del Mahatma. Por doquier surgen creativas maneras de resignificar la producción y la organización general de la economía (Coragio, 2005; Useche, 2009; Zibechi, 2011): ecoaldeas, clubes de trueque, recuperación para los trabajadores de industrias quebradas por las crisis del capital; reorganización autogestionaria de la economía campesina; nuevos modelos de cooperativismo y economía solidaria; experiencias de producción ecológica urbana, etc. Todas son formas de resistencia social, todas se inspiran en el bien de todos(as) y se proponen reconstruir lo común; cada una busca su propio camino para una economía noviolenta. 


\section{Notas}

1 Este texto es un producto de la investigación realizada para la construcción del estado del arte del proyecto "Lo común y los bienes comunes en la constitución de nuevas ciudadanías y territorialidades para la paz en Colombia” del Grupo de Investigación “Ciudanía, Paz y Desarrollo” de la Universidad Minuto de Dios en Bogotá (20152016). Recoge también aportes del estudio "Micropolítica de las resistencias sociales noviolentas (2014)” que fue publicado por la Universidad de Granada.

${ }^{2}$ Para este análisis el concepto tiene el siguiente sentido: "La dimensión micropolítica está constituida por la expresión, a menudo silenciosa o que apenas se percibe como un rumor, de miles de voces sometidas que comienzan a rebelarse, que manifiestan de muchas maneras su disposición a recuperar su dignidad, a volver a ser ellos mismos y no los sujetos moldeados desde el poder. La acción micropolítica discurre en clave de recuperación de la propia potencia, de generación de capacidades para reencontrase solidariamente con otros(as) sojuzgados(as) que ahora resisten. La micropolítica es una dimensión que permite captar la vida como heterogeneidad y variación, en donde la potencia de acción no está delimitada por territorios representados de poderes supremos, sino por micro-poderes que trazan nuevos trayectos y líneas por donde emerge el deseo, lo actual, lo novedoso”. (Useche, 2014: 33)

${ }^{3}$ La "Escuela de los estudios subalternos" ha desarrollado un importante trabajo para desarrollar investigaciones críticas a la visión eurocéntrica de la historia de las sociedades colonizadas. Surgió en la India como un grupo para proponer una alternativa a la historiografía desplegada desde los centros de poder colonial. El grupo fue fundado por con un Manifiesto publicado en Subaltern Studies y en su obra "Elementary Aspects of Peasant Insurgency” (1983). "En octubre 1998, hubo un congreso/diálogo en la DukeUniversity entre el Grupo Surasiático de Estudios Subalternos y el Grupo Latinoamericano de Estudios Subalternos" (Grosfoguel, R. http:// www.decolonialtranslation.com/espanol/transmodernidad-pensamiento-fronterizo-ycolonialidad-global.html). Un sector del grupo se pronunció por una crítica descolonial, “(...)que representa una crítica del eurocentrismo desde conocimientos subalternizados, inferiorizados y silenciados(...) (Mignolo, 2000:183-186; 213-214).

${ }^{4}$ Gayatry Ch. Spivak estudia ampliamente las implicaciones de esta lógica. Examinando los determinismos estructurales en cuanto al modelo productivo del capitalismo, y también los supuestos culturales y del lenguaje que hay allí planteados. Para el efecto ver: "Estudios de la subalternidad, deconstruyendo la historiografía” (Spivak, 1985: 330-363).

${ }^{5}$ El australiano Meaghan Morris, otro de los investigadores de los "Estudios culturales" critica esta visión de lo moderno concebido: “(...) como una historia conocida, algo que ya ha sucedido en otra parte, y que se reproducirá, mecánicamente o de otra manera, con un contenido local (...esto es...) el proyecto de la inoriginalidad positiva”. (Morris, 1996).

${ }^{6}$ A estos tópicos está dedicado el libro del sociólogo alemán Renate Zahar "Colonialismo y enajenación. Contribución a la teoría política de Frantz Fanon” en donde trae el pensamiento del autor en relación a la realidad argelina en su condición de colonia francesa. (Zahar, 1972). 
${ }^{7}$ Jonathan Schell el periodista norteamericano y activista contra la guerra nuclear y contra la guerra del Vietnam, recuerda en El mundo inconquistable que: "En un buque de vapor, durante su viaje de regreso a Sudáfrica (...), Gandhi escribió en su lengua materna de Guajarat el panfleto político más largo e incendiario de su vida, HindSwaraj (autogobierno indio), también denominado Sermon on the Sea ("Sermón en el mar"). En él abordaba directamente la cuestión de la occidentalización.” (Schell, 2005: 156157).

${ }^{8}$ El mismo autor calcula que, para la época de la revolución noviolenta, había en la India más de 500.000 aldeas lo que da cuenta de la inmensidad del problema referido. (Moore, 2002: 550).

${ }^{9}$ Pontara plantea que: "En Gandhi [...] la doctrina del ahimsa se traduce a nivel social en el sarvodaya, la sociedad "del bienestar de todos" que concretamente se articula en la propuesta de alternativas noviolentas a la violencia institucional, cultural y estructural intrínseca de ciertos sistemas sociales -para Gandhi, en primer lugar, del capitalismo imperialista y depredador y del industrialismo desenfrenado [...] el sarvodaya, [...] y los otros dos conceptos íntimamente relacionados de swaraj y swadeschi, [hacen parte de] los varios componentes sociales y políticos que, según Gandhi, caracterizan una sociedad del "bienestar de todos". (Pontara, Capítulo IX). En este mismo capítulo se refiere a nueve artículos que están incluidos en The Moral and PoliticalWritings of Mahatma Gandhi, vol. III, pp. 410-32 (Pontara, op. cit. Capítulo IX “Una sociedad del bienestar para todos”) en donde Gandhi desarrolla la idea.

${ }^{10}$ El fideicomiso propuesto por Gandhi es presentado así por Jeevan Kumar: "La idea gandhiana del Trusteeship surge de su fe en la ley de no-posesión. Se basaba en su creencia religiosa de que toda cosa pertenecía a Dios y venía de Dios. Todos los beneficios del universo estaban, pues, destinados a Su pueblo, en su totalidad, y no a un individuo en particular. Cuando un individuo obtenía más que la porción que le correspondía, se volvía fideicomisario (trustee) de esta porción, tenía que administrarla en favor del pueblo de Dios. Si este principio podía impregnarse en el pueblo en general, el Trusteeship se volvería una institución legalizada. Gandhi deseaba que esta institución llegara a ser un aporte de la India al resto del mundo”. (Kumar, 2007:2-3) 


\section{Bibliografía}

Ameglio, Pietro (2002),Gandhi y la Desobediencia Civil. México Hoy. Plaza y Valdés, México.

Coraggio, José L. (2005), ¿Es posible Otra Economía sin (otra) política? El pequeño libro socialista, Editora La Vanguardia, Buenos Aires.

Foucault, Michel (1987), La microfísica del poder. Ed. La Piqueta, Madrid.

Gandhi, Mohandas K. (2009) Autobiography. The Story of My Experiments With Truth, The Floating Press [1940], Auckland.

Gandhi, Mohandas K. (1977), Hacia un socialismo no violento. Las Pléyade, Buenos Aires.

Ídem (1982), Aldea y autonomía. La noviolencia como poder del pueblo. Ediciones Fiorentina, Florencia.

Ídem (2002), El Programa Constructivo de la India. En Ameglio, Pietro, Gandhi y la desobediencia civil. México hoy. Plaza y Valdés, Anexo II, pp, 301-332, México.

Gramsci, A. (1978), El concepto de hegemonía en Gramsci. Ed. Cultura popular, México.

Hardt, Michael \& Negri, Antonio (2011), Commonwealth. El proyecto de una revolución del común. Akal, Madrid.

La Boëtie, Etienne de (1986), Discurso de la servidumbre voluntaria o el Contra uno. Tecnos [1576], Madrid .

López Martínez, M. (2001), “La noviolencia como alternativa política”, en Muñoz, F. (Ed.) La Paz Imperfecta. Universidad de Granada, Granada, 181-251.

Ídem (2012), “Gandhi, política y satyagraha”, en Ra-Ximhai, vol 8, n² 2, pp. 39-70.

Ídem (2013), "Política sin matar. Los medios de la acción no-violenta", Vectores de investigación, $\mathrm{n}^{0}$ 7, pp. 33-84.

Martínez, Carlos E. (2012), De nuevo la vida. El poder de la Noviolencia y las transformaciones culturales. Corporación Universitaria Minuto de Dios, Bogotá.

Marx, Karl (1975), EL Capital. Fondo de cultura económica. México. [1867]. Ídem (2002), Elementos fundamentales para la crítica de la economía polí- 
tica. (Grundrisse) (1857-1858). Siglo XXI editores [1858], México.

Mignolo, Walter (2000), Local Histories/Global Designs: Essays on the Coloniality of Power, Subaltern Knowledges and Border Thinking, Princeton University Press, Princeton.

Moore, Barrington (2002), Los orígenes sociales de la dictadura y la democracia. Península, Barcelona.

Morris, Meaghan. 1996, “Banality in Cultural Studies”, en J. Storey (comp.), ¿What is Cultural Studies? A reader, Arnold., pp. 147-167, Londres.

Pontara, Giuliano (2004) “Gandhismo”, en López Martínez, Mario dir., Enciclopedia de paz y conflictos. Editorial Universidad de Granada, Granada, pp. 493-498.

Ídem (2006), L'antibarbarie. La concezione etico-politica di Gandhi e il XXI secolo. Edizione Gruppo Abele, Torino.

Ídem (2011), La Antibarbarie. La concepción ético política de Gandhi en el siglo XXI. Versión en español en proceso de publicación.

Rolland, Romain (1999), Gandhi. Ediciones Siglo XX. Buenos Aires (1962).

Santos, Boaventura de Sousa (coord.) (2011), Los caminos de la producción no capitalista. Fondo de Cultura Económica, Madrid.

Schell, Jonathan. (2005), EL mundo inconquistable. Poder, no violencia y voluntad popular. Círculo de lectores, Barcelona.

Spivak, Gayatri. (1985), "Estudios de la subalternidad. Deconstruyendo la historiografía”. En: Subaltern Studies IV. Guha, R. Editor. Oxford University Press. Delhi, pp. 330-363.

Thoreau, Henry David (2004), Del deber de la desobediencia civil. En Poder y democracia. FICA, [1848], Bogotá.

Useche, Óscar (2009), “Produciendo para la vida: ejercicios de economías en resistencia”, en: Martínez, Espejo \& Useche (comp), Noviolencia: creando mundos posibles. Uniminuto, Bogotá, 119-148.

Ídem (2014), Micropolítica de las resistencias sociales noviolentas. El acontecimiento de las resistencias como apertura de nuevos territorios existenciales. Universidad de Granada, Granada.

Zahar, Renate. (1972), Colonialismo y Enajenación. Contribución a la teoría política de Frantz Fanon. Siglo XXI Editores, Buenos Aires.

Zibechi, Raúl (2011), Autonomías y emancipaciones: América Latina en 
movimiento, editoriales Bajo Tierra y Sísifo, México.

\section{Sitios web}

Chakrabarty, Dipesh (1999), La poscolonialidad y el artilugio de la historia: ¿quién habla en nombre de los pasados “indios”? CEAA, Centro de Estudios de Asia y África del Colegio de México. México, DF. (Fecha de consulta: 9 de mayo 2014). Disponible en: http://bibliotecavirtual. clacso.org.ar/Mexico/ceaa-colmex/20100410122627/chakra.pdf

Grosfoguel, R. La Descolonización de la Economía Política y los Estudios Postcoloniale.Transmodernidad, pensamiento fronterizo y colonialidad global. Disponible en: http://www.decolonialtranslation.com/espanol/ transmodernidad-pensamiento-fronterizo-y-colonialidad-global.html

Marx, Karl (2000), La dominación británica en la India. Marxists internet archive. (Fecha de consulta: 11 de noviembre 2013). Disponible en: : http:/ /www.marxists.org/espanol/m-e/1850s/25-vi-1853.htm

Recibido: 30.01.2016

Aceptado: 05.04.2016 